\title{
Analisis Pengaruh Kompensasi Dan Gaya Kepemimpinan Terhadap Kinerja Karyawan Pada PT. Surya Rasa Loka Jaya Di Jakarta Barat
}

\author{
${ }^{1}$ Muhammad Gandung, ${ }^{2}$ Suwanto \\ Dosen Fakultas Ekonomi Universitas Pamulang \\ Email : ${ }^{1}$ dosen02020@unpam.ac.id, ${ }^{2}$ dosen01813@unpam.ac.id
}

\begin{abstract}
ABSTRAK
Penelitian ini bertujuan untuk mengetahui bagaimana kompensasi karyawan, bagaimana gaya kepemimpinan, bagaimana kinerja karyawan dan bagaimana pengaruh kompensasi dan gaya kepemimpinan terhadap kinerja pada PT Surya Loka Rasa Jaya

Populasi dalam penelitian ini adalah seluruh karyawan PT Surya Loka Rasa Jaya yang berjumlah 57 orang. Teknik sampel yang digunakan adalah Sampling jenuh dimana semua semua anggota populasi dijadikan sampel. Pengumpulan data primer dilakukan dengan menggunakan observasi, kuesioner dan wawancara tertutup yang diukur dengan skala likert. Data sekunder diperoleh dari dokumentasi dan studi kepurtakaan. teknik analisis yang digunakan meliputi uji validitas, uji reliabilitas, uji normalitas, uji multikolinearitas, uji heteroskedastisitas, uji autokorelasi, uji korelasi berganda, uji regresi linear berganda, uji koefisien determinasi, uji t dan uji $\mathrm{f}$.

Dari hasil analisis deskriptif, kompensasi memiliki nilai rata-rata sebesar 3,73 maka kompensasi karyawan pada PT Surya Loka Rasa Jaya dikatakan baik, dari hasil analisis deskriptif, gaya kepemimpinan memiliki nilai rata-rata sebesar 3,95 maka gaya kepemimpinan pada PT Surya Loka Rasa Jaya dikatakan baik, dan dari hasil analisis deskriptif, kinerja karyawan memiliki, nilai rat-rata sebesar 3,84 maka kinerja karyawan pada PT Surya Loka Rasa Jaya dikatakan baik. Dari hasil uji t kompensasi $\left(\mathrm{x}_{1}\right)$ terhadap kinerja $(\mathrm{y})$ menunjukan nilai $\mathrm{t}_{\text {hitung }}(6,399)>\mathrm{t}_{\text {tabel }}(2,005)$ dan sig $(0,000)<0,05$, dan gaya kepemimpinan $\left(\mathrm{x}_{2}\right)$ terhadap kinerja $(\mathrm{y})$ menunjukan nilai thitung $(3,485)>t_{\text {tabel }}(2,005)$ dan sig $(0,004)<0,05$, sehingga $\mathrm{H}_{a 1}$ dan $\mathrm{H}_{\mathrm{a} 2}$ diterima maka terdapat pengaruh yang positif dan signifikan. Dari hasil uji f kompensasi $\left(\mathrm{x}_{1}\right)$ dan gaya kepemimpinan $\left(\mathrm{x}_{2}\right)$ secara bersama-sama terhadap kinerja (y) menunjukan nilai $f_{\text {hitung }}(68,361)>f_{\text {tabel }}(3,17)$ dan sig $(0,000)<0,05$, sehingga $\mathrm{H}_{23}$ diterima maka terdapat pengaruh yang positif dan signifikan. Melalui pengujian koefisien determinasi $\left(\mathrm{R}^{2}\right)$ diperoleh sebesar 0,717 sama dengan $71,7 \%$ yang berarti kompensasi $\left(\mathrm{x}_{1}\right)$ dan gaya kepemimpinan $\left(\mathrm{x}_{2}\right)$ berpengaruh kuat terhadap kinerja (y) dan sisanya 39,3\% dipengaruhi oleh variabel lain yang tidak diteliti dalam penelitian ini.
\end{abstract}

\section{Kata Kunci : Kompensasi, Gaya kepemimpinan dan Kinerja.}




\section{PENDAHULUAN}

Manajemen adalah salah satu bagian terpenting dalam suatu perusahaan. Tugasnya sangat penting dalam suatu organisasi yakni menentukan dan mengawasi kinerja suatu organisasi agar dapat mencapai tujuan yang telah di tetapkan oleh manajemen itu sendiri. Dari sini dapat diketahui bahwa manajemen mutlak diperlukan dalam suatu organisasi karena pusat kinerja dari organisasi itu sendiri.

Sumber daya manusia adalah ilmu yang mempelajari bagaimana memberdayakan karyawan dalam perusahaan, membuat pekerjaan, kelompok kerja, mengembangkan para karyawan yang mempunyai kemampuan mengidentifikasi suatu pendekatan untuk dapat mengembangkan kinerja karyawan dan memberikan imbalan kepada mereka atas usahanya dalam bekerja, Bohlarander dan Snell (2010:4). Peranan Sumber Daya Manusia memiliki kedudukan yang sangat penting dalam sebuah organisasi dalam mencapai tujuan sebuah perusahaan. Sumber Daya Manusia sangat penting bagi perusahaan dalam mengelola, mengatur, dan memanfaatkan pegawai sehingga dapat berfungsi sebagai secara produktif umtuk tercapainya tujuan suatu perusahaan. Sumber Daya Manusia sebagai penggerak organisasi dalam mencapai tujuan, harus mendorong upaya - upaya karyawan untuk bekerja lebih giat. Dengan adanya karyawan yang bekerja lebih giat dan lebih baik maka diharapkan hasil kerja karyawan yang baik juga dapat di capai oleh karyawan dalam melakukan tugas dan pekerjaannya.
Tujuan perusahaan dapat tercapai bukan tergantung pada peralatan kerja yang canggih dan modern, sarana dan prasarana yang lengkap namun lebih tergantung pada manusia yang melaksanakan pekerjaan tersebut. Keberhasilan suatu organisasi sangat dipengaruhi oleh setiap individu karyawannya. Setiap organisasi maupun perusahaan akan selalu berusaha untuk meningkatkan kinerja karyawannya dengan harapan dapat tercapainya tujuan perusahaan.

Ada beberapa cara untuk mewujudkan kinerja yang baik dapat di capai dengan melalui pendidikan, pelatihan, pemberian kompensasi yang layak, menciptakan lingkungan kerja yang kondusif dan pemberian motivasi. Pemberian motivasi untuk meningkatkan kinerja pada pegawai menyangkut berbagai bentuk, di antaranya dengan cara memberi motivasi langsung tertuju pada masing - masing individu. Cara lain yang lazim di laksanakan adalah dengan memberikan kebijaksanaan kompensasi yang wajar, yang bisa mencukupi kebutuhan hidupnya.

Pada kesempatan kali ini saya meneliti sebuah perusahaan bernama PT Surya Loka Rasa Jaya yaitu sebuah perusahaan yang bergerak di bidang properti, yang menjual rumah, apartemen bahkan kios dengan Brand "Lavanya Hills Residences" untuk perumahan dan "Lavanya Garden Residences" untuk apartemen dan kios. Perusahaan ini sudah berdiri sejak 30 tahun lalu, namun untuk proyek 'LHR-LGR” Brand ini disebut, sudah berdiri sejak tahun 2012 di Cinere, Depok. PT Surya Loka Rasa Jaya ini memiliki cukup banyak karyawan yang dipekerjakan, dan 
setiap bulannya karyawan selalu diberikan kompensasi berupa gaji dan insentif, biasanya diberikan pada akhir bulan (untuk gaji) dan pertengahan bulan (untuk insentif).

Namun ada beberapa permasalahan yang terjadi pada kinerja karyawan dikarenakan soal kompensasi dan gaya kepemimpinan perusahaan di PT Surya Loka Rasa Jaya ini yaitu tingkat turn over karyawan atau sering terjadinya karyawan yang keluar masuk di setiap bulannya pada beberapa divisi. Permasalahan lain adalah masih banyak nya karyawan yang mangkir kerja dengan berbagai alasan serta tingkat keterlambatan karyawan yang masih cukup tinggi.

Berdasarkan uraian di atas, peneliti tertarik untuk melakukan penelitian dengan judul "Pengaruh Kompensasi dan Gaya Kepemimpinan Terhadap Kinerja Karyawan PT Surya Loka Rasa Jaya”.

\section{RUMUSAN MASALAH}

Dari uraian latar belakang permasalahan, maka masalah yang diteliti selanjutnya dapat dirumuskan sebagai berikut :

1. Seberapa besar pengaruh kompensasi terhadap kinerja pada PT Surya Loka Rasa Jaya

2. Seberapa besar pengaruh gaya kepemimpinan terhadap kinerja pada PT Surya Loka Rasa Jaya

3. Seberapa besar pengaruh kompensasi dan gaya kepemimpinan terhadap kinerja pada PT Surya Loka Rasa Jaya

\section{KAJIAN TEORI}

\section{KOMPENSASI}

Kompensasi adalah semua pendapatan yang berbentuk uang, barang langsung atau tidak langsung yang diterima karyawan sebagai imbalan atas jasa yang diberikan kepada karyawan oleh perusahaan.

\section{GAYA KEPEMIMPINAN}

Gaya kepemimpinan adalah suatu bakat yang diperoleh orang sebagai kemampuan istimewa yang dibawa sejak lahir.

\section{KINERJA}

Kinerja adalah hasil kerja secara kualitas yang di capai oleh seorang pegawai dalam melaksanakan tugasnya sesuai dengan tanggung jawab yang diberikan kepadanya

\section{METODE PENELITIAN}

Penelitian ini dilakukan pada PT Surya Loka Rasa Jaya yang beralamatkan Jl. Bukit Cinere Raya, Cinere-Depok. Dengan luas area 8 ha Lavanya Hills Residences. Teknik sampel yang digunakan adalah Sampling jenuh dimana semua semua anggota populasi dijadikan sampel. Pengumpulan data primer dilakukan dengan menggunakan observasi, kuesioner dan wawancara tertutup yang diukur dengan skala likert.

Data sekunder diperoleh dari dokumentasi dan studi kepurtakaan. teknik analisis yang digunakan meliputi uji validitas, uji reliabilitas, uji normalitas, uji multikolinearitas, uji heteroskedastisitas, uji autokorelasi, uji korelasi berganda, uji regresi linear berganda, uji koefisien determinasi, uji t dan uji f. dengan jumlah populasi 57 orang. 


\section{HASIL PENELITIAN DAN PEMBAHASAN \\ Karakteristik Responden}

Responden dalam penelitian ini adalah karyawan PT Surya Loka Rasa Jaya, dengan jumlah responden sebanyak 57 orang karyawan.

\section{Uji Koefisien Determinasi}

Uji koefisien determinasi dilakukan untuk mengetahui seberapa besar tingkat pengaruh variabel kompensasi $\left(\mathrm{x}_{1}\right)$ dan gaya kepemimpinan $\left(\mathrm{x}_{2}\right)$ terhadap variabel kinerja (y) dengan menggunakan rumus $\mathrm{KD}=\mathrm{R}^{2} \times 100 \%$ dan jika $K d$ mendekati satu (1), memiliki arti tingkat pengaruh variable independent terhadap variable dependen kuat.

\section{a. Uji Koefisien Determinasi Kompensasi $\left(\mathrm{x}_{1}\right)$ terhadap Kinerja (y)}

Untuk mengetahui seberapa besar tingkat pengaruh variabel kompensasi $\left(\mathrm{x}_{1}\right)$ terhadap variabel kinerja $(\mathrm{y})$ dengan melihat nilai $\mathrm{R}$ Square pada hasil pengujian uji koefisien determinasi yang diolah dengan menggunakan program SPSS versi 22 sebagai berikut :

\section{Tabel 1}

Uji Koefisien Determinasi

Kompensasi $\left(\mathbf{X}_{1}\right)$ Terhadap Kinerja (Y)

\begin{tabular}{cc|c|c|c} 
Model & R & $\begin{array}{c}\text { Model Summary } \\
\text { R }\end{array}$ & $\begin{array}{c}\text { Adjusted } \\
\text { R Square }\end{array}$ & $\begin{array}{c}\text { Std. } \\
\text { Error of the } \\
\text { Estimate }\end{array}$ \\
\hline 1 & $.808^{\mathrm{a}}$ & .653 & .647 & 2.785 \\
\hline
\end{tabular}

a. Predictors: (Constant), Kompensasi

Sumber : Hasil Pengolahan data SPSS (2019)

Berdasarkan tabel diatas di peroleh nilai $\mathrm{R}^{2}$ ( $\mathrm{R}$ Square) yaitu 0,653 mendekati satu (1), berarti variabel kompensasi $\left(\mathrm{x}_{1}\right)$ terhadap variabel kinerja (y) kuat. Maka dapat disimpulkan bahwa variabel kompensasi $\left(\mathrm{x}_{1}\right)$ terhadap variabel kinerja (y) pada PT Surya Loka Rasa Jaya berpengaruh kuat sebesar $65,3 \%$ dan sisanya $34,7 \%$ dipengaruhi oleh variabel lain yang tidak diteliti dalam penelitian ini.

b. Uji Koefisien Determinasi Gaya Kempemimpinan ( $\left.\mathbf{x}_{2}\right)$ terhadap kinerja (y)

Untuk mengetahui seberapa besar tingkat pengaruh variabel gaya kepemimpinan $\left(\mathrm{x}_{2}\right)$ terhadap variabel kinerja $(\mathrm{y})$ dengan melihat nilai $\mathrm{R}$ Square pada hasil pengujian uji koefisien determinasi yang diolah dengan menggunakan program SPSS versi 22 sebagai berikut :

Tabel 2

Hasil Uji Koefisien Determinasi

Gaya Kepemimpinan $\left(\mathbf{X}_{2}\right)$

Terhadap Kinerja (Y)

Model Summary

Std. Error

R Adjusted R of the

\begin{tabular}{lllll} 
Model & R & \multicolumn{2}{l}{ Square Square } & Estimate \\
\hline 1 & $.709^{\mathrm{a}}$ & .502 & .493 & 3.337 \\
\hline
\end{tabular}

a. Predictors: (Constant), Gaya Kepemimpinan

Sumber : Hasil Pengolahan data SPSS (2019)

Berdasarkan tabel diatas di peroleh nilai $\mathrm{R}^{2}$ ( $\mathrm{R}$ Square) yaitu 0,502 mendekati satu (1), berarti variabel gaya kepemimpinan $\left(\mathrm{x}_{2}\right)$ terhadap variabel kinerja (y) kuat. Maka dapat disimpulkan bahwa variabel kompensasi $\left(\mathrm{x}_{1}\right)$ terhadap variabel kinerja (y) pada PT Surya Loka Rasa Jaya berpengaruh kuat sebesar 50,2\% dan sisanya $49,8 \%$ dipengaruhi 
oleh variabel lain yang tidak diteliti dalam penelitian ini.

c. Uji Koefisien Determinasi Kompensasi ( $\left.\mathbf{x}_{1}\right)$ dan Gaya Kepemimpinan $\left(\mathrm{x}_{2}\right)$ terhadap kinerja (y)

Untuk mengetahui seberapa besar tingkat pengaruh variabel kompensasi $\left(\mathrm{x}_{1}\right)$ dan gaya kepemimpinan $\left(\mathrm{x}_{2}\right)$ terhadap variabel kinerja (y) dengan melihat nilai $\mathrm{R}$ Square pada hasil pengujian uji koefisien determinasi yang diolah dengan menggunakan program SPSS versi 22 sebagai berikut :

\section{Tabel 3}

Uji Koefisien Determinasi

Kompensasi ( $\left.\mathbf{X}_{1}\right)$ Dan Gaya

Kepemimpinan $\left(\mathbf{X}_{2}\right)$ Terhadap

Kinerja (Y)

Model Summary

$\mathrm{R}$

Adjusted the

Std.

Error of

Model R Square R SquareEstimate

\begin{tabular}{llll}
\hline 1 & $.847^{\mathrm{a}} .717$ & .706 & 2.540 \\
\hline
\end{tabular}

a. Predictors: (Constant), Gaya Kepemimpinan, Kompensasi

Sumber : Hasil Pengolahan data SPSS (2019)

Berdasarkan tabel diatas di peroleh nilai $\mathrm{R}^{2}$ ( $\mathrm{R}$ Square) yaitu 0,717 mendekati satu (1), berarti variabel kompensasi $\left(\mathrm{x}_{1}\right)$ dan gaya kepemimpinan terhadap variabel kinerja (y) kuat. Maka dapat disimpulkan bahwa variabel kompensasi $\left(\mathrm{x}_{1}\right)$ dan gaya kempemimpinan $\left(\mathrm{x}_{1}\right)$ terhadap variabel kinerja (y) pada PT Surya Loka Rasa Jaya berpengaruh kuat sebesar 71,7\% dan sisanya 39,3\% dipengaruhi oleh variabel lain yang tidak diteliti dalam penelitian ini.

Langkah-langkah dalam melakukan uji koefisien determinasi dengan menggunakan program SPSS tersebut sama seperti uji koefisien korelasi berganda maka cukup memperhatikan hasil yang terdapat pada tabel Model Summary pada kolom $R$ Square.

\section{Uji Parsial (uji t)}

Uji t digunakan untuk menguji pengaruh parsial antara variabel kompensasi $\left(\mathrm{x}_{1}\right)$ dan gaya kepemimpinan $\left(\mathrm{x}_{2}\right)$ terhadap kinerja (y) dengan $\alpha=5 \%$. Kreteria pengujian dalam penelitian ini adalah sebagai berikut :

a. Berdasarkan perbandingan Sig dengan $\alpha=5 \%(0,05 \%)$.

1) Jika Sig. < 0,05, maka $\mathrm{H}_{\mathrm{a}}$ diterima dan $\mathrm{H}_{0}$ ditolak artinya secara masing-masing terdapat pengaruh signifikan antara kompensasi $\left(\mathrm{x}_{1}\right)$ dan gaya kepemimpinan $\left(\mathrm{x}_{2}\right)$ terhadap kinerja (y)

2) Jika Sig. > 0,05, maka $\mathrm{H}_{\mathrm{a}}$ ditolak dan $\mathrm{H}_{0}$ diterima secara masing-masing tidak terdapat pengaruh signifikan antara kompensasi $\left(\mathrm{x}_{1}\right)$ dan gaya kepemimpinan $\left(\mathrm{x}_{2}\right)$ terhadap kinerja (y)

b. Perbandingan dengan $t_{\text {hitung }}$ dengan $t_{\text {tabel }}$

1) Jika $t_{\text {hitung }}>t_{\text {tabel, }}$, maka $\mathrm{H}_{\mathrm{a}}$ diterima dan $\mathrm{H}_{0}$ ditolak secara masing-masing terdapat pengaruh kompensasi $\left(\mathrm{x}_{1}\right)$ dan gaya kepemimpinan $\left(\mathrm{x}_{2}\right)$ terhadap kinerja (y) 
2) Jika $t_{\text {hitung }}<t_{\text {tabel, }}$ maka $H_{a}$ ditolak dan $\mathrm{H}_{0}$ diterima masing-masing tidak terdapat pengaruh kompensasi $\left(\mathrm{x}_{1}\right)$ dan gaya kepemimpinan $\left(\mathrm{x}_{2}\right)$ terhadap kinerja (y)

c. Menentukan nilai tabel dengan derajat kepercayaan $95 \%(\alpha=$ $5 \%$ )

Derajat kebebasan/degree of freedom $(\mathrm{df})=(\mathrm{n}-\mathrm{k})$ 2,005

$\mathrm{df}=(\mathrm{n}-\mathrm{k})=57-3=54, \mathrm{t}_{\text {tabel }}=$

Hasil pengujian uji parisal yang diolah dengan menggunakan program SPSS versi 24 sebagai berikut :

\section{Tabel 4}

Hasil Uji Parsial (uji t)

Coefficients $^{\text {a }}$

Unstandar Standar

dized dized

Coefficien Coeffici

ts

ents

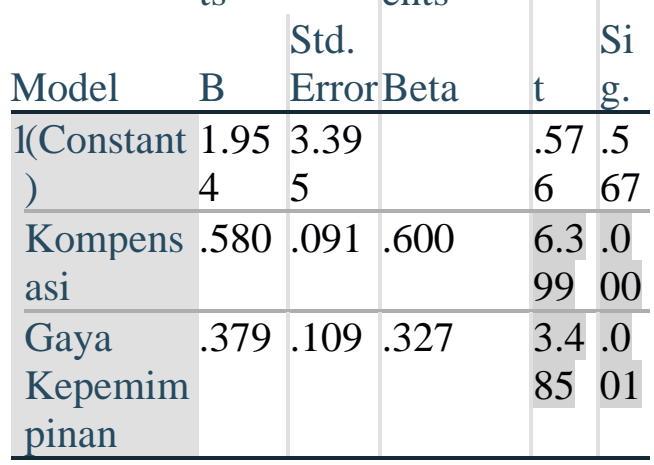

a. Dependent Variable: Kinerja

Karyawan

Sumber : Hasil Pengolahan data SPSS (2019)

Berdasarkan tabel diatas pengaruh dari masing-masing variabel dapat disimpulkan sebagai berikut :

a. Pengaruh kompensasi $\left(\mathrm{x}_{1}\right)$ terhadap kinerja $(\mathrm{y})$

Hasil uji parsial antara kompensasi terhadap kinerja menunjukan nilai $\mathrm{t}_{\text {hitung }}(6,399)>\mathrm{t}_{\text {tabel }}(2,005)$ dan sig $(0,000)<0,05$, sehingga $\mathrm{H}_{\mathrm{a} 1}$ diterima maka terdapat pengaruh yang positif dan signifikan antara kompensasi terhadap kinerja pada PT Surya Loka Rasa Jaya

b. Pengaruh gaya kepemimpinan $\left(\mathrm{x}_{2}\right)$ terhadap kinerja $(\mathrm{y})$

Hasil uji parsial antara gaya kepemimpinan terhadap kinerja menunjukan nilai $t_{\text {hitung }}(3,485)>t_{\text {tabel }}$ $(2,005)$ dan sig $(0,001)<0,05$ sehingga $\mathrm{H}_{\mathrm{a} 2}$ diterima maka terdapat pengaruh yang positif dan signifikan dari gaya kepemimpinan terhadap kinerja pada PT Surya Loka Rasa Jaya

Langkah-langkah dalam melakukan uji uji Parsial (uji t) dengan menggunakan software SPSS tersebut sama seperti uji regresi linier berganda dengan melihat hasil hasil regresi linier berganda pada tabel Coefficients ${ }^{a}$ pada kolom $t$.

\section{Uji Simultan (uji f)}

Uji simultan digunakan untuk mengetahui apakah secara simultan koefisien variabel kompensasi $\left(\mathrm{x}_{1}\right)$ dan gaya kepemimpinan $\left(\mathrm{x}_{2}\right)$ mempunyai pengaruh nyata atau tidak terhadap variabel kinerja (y) dengan $a=0,05$. Kriteria pengujian dalam penelitian ini adalah sebagai berikut :

a. Berdasarkan perbandingan Sig. Dengan $\alpha=5 \%(0,05)$.

1) JikaSig. $<0,05$, maka $\mathrm{H}_{\mathrm{a}}$ diterima dan $\mathrm{H}_{0}$ ditolak artinya secara bersama-sama terdapat pengaruh signifikan antara kompensasi $\left(\mathrm{x}_{1}\right)$ dan gaya kepemimpinan $\left(\mathrm{x}_{2}\right)$ terhadap kinerja (y)

2) Jika Sig. > 0,05, maka $\mathrm{H}_{a}$ ditolak dan $\mathrm{H}_{0}$ diterima artinya secara bersama-sama tidak terdapat pengaruh signifikan antara kompensasi $\left(\mathrm{x}_{1}\right)$ dan gaya kepemimpinan $\left(\mathrm{x}_{2}\right)$ terhadap kinerja $(\mathrm{y})$ 
b. Berdasarkan perbandingan $F_{\text {hitung }}$ dengan $F_{\text {tabel. }}$.

1) Jika $F_{\text {hitung }}>F_{\text {Tabel, }}$ maka $\mathrm{H}_{\mathrm{a}}$ diterima dan $\mathrm{H}_{0}$ ditolak artinya secara bersama-sama terdapat pengaruh kompensasi $\left(\mathrm{x}_{1}\right)$ dan gaya kepemimpinan $\left(\mathrm{x}_{2}\right)$ terhadap kinerja (y)

2) Jika $F_{\text {hitung }}<F_{\text {Tabel, }}$ maka $\mathrm{H}_{\mathrm{a}}$ ditolak dan $\mathrm{H}_{0}$ diterima artinya secara bersama-sama tidak terdapat pengaruh kompensasi $\left(\mathrm{x}_{1}\right)$ dan gaya kepemimpinan $\left(\mathrm{x}_{2}\right)$ terhadap kinerja (y)

c. Menentukan nilai $\mathrm{F}_{\text {tabel }}$ dengan derajat kepercayaan $95 \%(\alpha=$ $5 \%)$ $\mathrm{n}-\mathrm{k}-1)$

$\mathrm{f}_{\text {tabel }}=\left(\mathrm{df}_{\text {pembilang }}=\mathrm{k} ; \mathrm{df}_{\text {penyebut }}=\right.$

$\mathrm{f}_{\text {tabel }}=(\mathrm{k} ; \mathrm{n}-\mathrm{k}-1)=(2 ; 57-2-1)$

$=(2 ; 54) \mathrm{f}_{\text {tabel }}=3,17$

Hasil pengujian uji simultan yang diolah dengan menggunakan program SPSS versi 22 sebagai berikut:

\section{Tabel 5}

Hasil Uji Simultan (uji F)

ANOVA $^{a}$

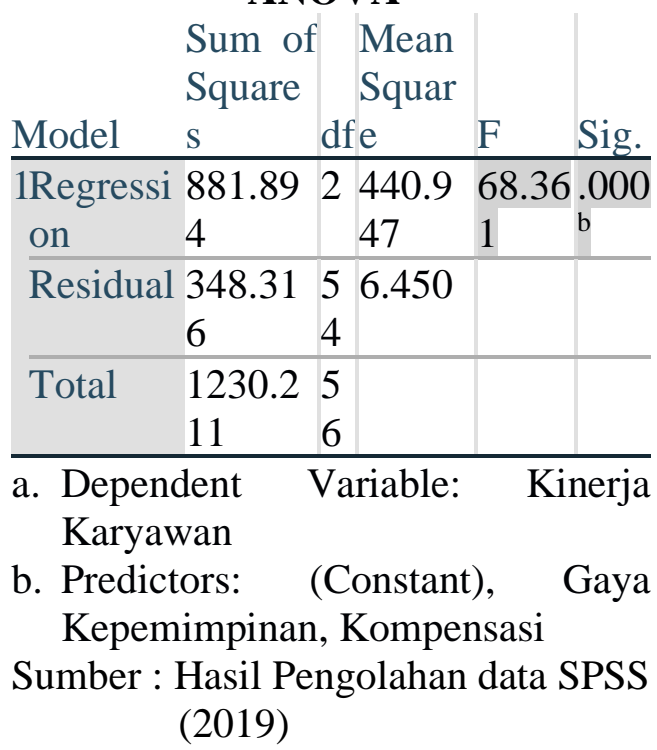

Berdasarkan tabel diatas pengaruh pengaruh variabel kompensasi $\left(\mathrm{x}_{1}\right)$ dan gaya kepemimpinan $\left(\mathrm{x}_{2}\right)$ secara bersamasama terhadap kinerja (y) menunjukan nilai $f_{\text {hitung }}(68,361)>f_{\text {tabel }}(3,17)$ dan sig $(0,000)<0,05$, sehingga $\mathrm{H}_{\mathrm{a} 3}$ diterima maka terdapat pengaruh yang positif dan signifikan antara kompensasi dan gaya kepemimpinan secara bersama-sama terhadap kinerja pada PT Surya Loka Rasa Jaya

Langkah-langkah melakukan uji simultan dengan menggunakan software SPSS tersebut sama seperti uji regresi linier berganda dengan melihat hasil regresi linier berganda pada tabel Anova pada kolom F.

\section{KESIMPULAN DAN SARAN}

\section{A. Kesimpulan}

Berdasarkan rumusan permasalahan dan hasil analisis mengenai kompensasi dan gaya kepemimpinan terhadap kinerja dapat disimpulkan sebagai berikut :

1. Berdarakan hasil analisis deskriptif, kompensasi memiliki nilai rata-rata yaitu sebesar 3,73 termasuk pada rentang skala 3,41 - 4,20 dengan kriteria baik, dari variabel kompensasi dapat dilihat bahwa responden yang memilih jawaban kuesioner sangat setuju (SS) sebesar 25\%, memilih jawaban kusioner setuju (S) sebesar 37\%, memilih jawaban kuesioner kurang setuju (KS) sebesar 26\%, memilih jawaban kuesioner tidak setuju (TS) sebesar $11,7 \%$, dan yang memilih jawaban kuesioner sangat tidak setuju (STS) sebesar 1,92\%. Maka dapat disimpulkan bahwa presentase jawaban kuesioner variabel kompensasi terbesar yaitu 
setuju dengan presentase sebesar $37 \%$.

2. Berdarakan hasil analisis deskriptif, gaya kepemimpinan memiliki nilai rat-rata yaitu sebesar 3,95 termasuk pada rentang skala $3,41-4,20$ dengan kriteria baik, dari variabel gaya kepemimpinan dapat dilihat bahwa responden yang memilih jawaban kuesioner sangat setuju (SS) sebesar 30,5\%, memilih jawaban kusioner setuju (S) sebesar $42,1 \%$, memilih jawaban kuesioner kurang setuju (KS) sebesar 20,1\%, memilih jawaban kuesioner tidak setuju (TS) sebesar 6\%, dan yang memilih jawaban kuesioner sangat tidak setuju (STS) sebesar $1 \%$. Maka dapat disimpulkan bahwa presentase jawaban kuesioner variabel gaya kepemimpinan terbesar yaitu setuju dengan presentase sebesar $\mathbf{4 2 , 1 \%}$.

3. Berdarakan hasil analisis deskriptif, kinerja memiliki nilai rat-rata yaitu sebesar 3,84 termasuk pada rentang skala 3,41 - 4,20 dengan kriteria baik, dari variabel kinerja dapat dilihat bahwa responden yang memilih jawaban kuesioner sangat setuju (SS) sebesar 29,8\%, memilih jawaban kusioner setuju (S) sebesar $36,1 \%$, memilih jawaban kuesioner kurang setuju (KS) sebesar $24,2 \%$, memilih jawaban kuesioner tidak setuju (TS) sebesar 8,5\%, dan yang memilih jawaban kuesioner sangat tidak setuju (STS) sebesar 1,2\%. Maka dapat disimpulkan bahwa presentase jawaban kuesioner variabel kinerja terbesar yaitu setuju dengan presentase sebesar $36,1 \%$.

4. Kompensasi dan gaya kepemimpinan secara bersamasama terhadap kinerja menunjukan nilai $\mathrm{f}_{\text {hitung }}(68,361)>\mathrm{f}_{\text {tabel }}(3,17)$ dan sig $(0,000)<0,05$, sehingga $\mathrm{H}_{\mathrm{a} 3}$ diterima maka terdapat pengaruh yang positif dan signifikan antara kompensasi dan gaya kepemimpinan secara bersamasama terhadap kinerja pada PT Surya Loka Rasa Jaya Dengan persamaan regresi $\mathrm{Y}=1,954+$ $0,580 \mathrm{x}_{1}+0,379 \mathrm{x}_{2}$ serta kompensasi dan gaya kempemimpinan terhadap variabel kinerja pada PT Surya Loka Rasa Jaya berpengaruh kuat sebesar $71,7 \%$ dan sisanya 39,3\% dipengaruhi oleh variabel lain yang tidak diteliti dalam penelitian ini.

\section{B. Saran}

Berdasarkan hasil penelitian pada analisis desktiptif variabel yang diperoleh, maka saran yang diberikan adalah sebagai berikut :

1. Meskipun kompensasi dikategorikan baik, terdapat butir pernyataan dengan nilai presentase tidak setuju (TS) paling tinggi yaitu sebesar $24,5 \%$ pada pernyataan " Besarnya gaji pokok yang diterima karyawan sesuai dengan pekerjaan yang dilakukan". Maka pihak perusahaan harus memperhatikan dan menimbang kembali besarnya gaji pokok yang diterima karyawan harus disesuaikan dengan pekerjaan yang dilakukan oleh karyawan tesebut.

2. Meskipun gaya kepeimpinan dikategorikan baik, terdapat butir pernyataan dengan nilai presentase tidak setuju (TS) paling tinggi yaitu sebesar $21 \%$ pada pernyataan “" Pimpinan memberikan kenyamanan bagi karyawannya ". Maka pihak perusahaan lebih memberikan perhatiannya kepada karyawan berupa rasa aman dan 
nyaman berada di perusahaan yang dapat memicu kinerja karyawan.

3. Meskipun kinerja dikategorikan baik, terdapat butir pernyataan dengan nilai presentase tidak setuju (TS) paling tinggi yaitu $22,8 \%$ pada pernyataan

"Karyawan menyelesaikan tugas sesuai dengan kualitas yang diinginkan perusahaan" dan "Karyawan mempunyai inisiatif dalam melakukan pekerjaan”. Maka pihak perusahaan harus mempertimbangkan kompensasi berupa gaji kepada karyawan dan meningkatkan kembali perhatian yang diberikan dari pimpinan kepada karyawannya agar karyawan dapat menyelesaikan tugas dan tanggung jawabnya dengan baik serta dapat meningkatkan inisiatif dalam melakukan pekerjaan.

\section{DAFTAR PUSTAKA}

Abdullah. 2014. Manajemen dan Evaluasi Kinerja Karyawan. Yogyakarta: Penerbit Aswaja Pressindo.

Arikunto. 2013. Prosedur Penelitian Suatu Pendekatan Praktik. Jakarta: Rineka Cipta.

Bohlander, and Snell. 2010. Principles of Human Resource. Management, 15th ed. Mason, $\mathrm{OH}$ : South Western - Cengage Learning

Dessler. 2015. Manajemen Sumber Daya Manusia. Jakarta: Salemba Empat.

Ghozali. 2013. Aplikasi Analisis Multivariate dengan Program IBM SPSS 21 Update PLS Regresi. Semarang: Badan Penerbit Universitas Diponegoro.
Hasibuan. 2012. Manajemen Sumber Daya Manusia, Edisi Revisi, Jakarta: Bumi Aksara

Kartono. 2014. Pemimpin dan Kepemimpinan. Jakarta : PT Raja Grafindo Persada.

Mangkunegara. 2013. Manajemen Sumber Daya Manusia Perusahaan. Bandung: Remaja Rosdakarya.

Rialmi, Z., \& Morsen, M. (2020). Pengaruh Komunikasi Terhadap Kinerja Karyawan PT Utama Metal Abadi. JENIUS, 3(2), 221-227.

Rialmi, Z. (2017). Pengaruh Keadilan Prosedural Yang Diterapkan Kepemimpinan Pegawai Dan Kepuasan Kerja Pegawai Terhadap Kinerja Dari Pegawai BPBD Provinsi Riau. Jurnal Mandiri: Ilmu Pengetahuan, Seni, dan Teknologi, 1(2), 353374.

Simamora. 2015. Manajemen Sumber Daya Manusia. Yogyakarta: STIEY

Sugiyono. 2012. MetodePenelitian Kuantitatif dan Kualitatif dan $R \& D$ Bandung: Alfabeta

Sunarsi, D. (2018). Pengaruh Kompensasi, Komunikasi Dan Stress Kerja Terhadap Prestasi Kerja Karyawan Pada PT Catur Putra Jaya Kota Depok-Jawa Barat. JIMF (Jurnal Ilmiah Manajemen Forkamma), 1(2).

Sunarsi, D. (2020). Panduan Meningkatkan Kinerja Dan Kepuasan Guru. Kota Serang: Desanta Muliavisitama

Sunarsi, D. (2019). Seminar Sumber Daya Manusia. Tangerang Selatan: Unpam Press 
Sunarsi, D. (2018). Buku Ajar: Seminar Perencanaan Sumber Daya Manusia. Tangerang Selatan: Asmoro Mediatama Sunyoto. 2016. Metodologi Penelitian Akuntansi. Bandung: PT Refika Aditama.

Suwanto, S. (2019). Pengaruh Disiplin Kerja Dan Motivasi Kerja Terhadap Kinerja Karyawan Pada Rumah Sakit Umum Tangerang Selatan. JENIUS, 3(1), 16-23.
Suwanto, S. (2019). Pengaruh Gaya Kepemimpinan Dan Lingkungan Kerja Terhadap Kinerja Karyawan Unit Telesales Pada PT BFI Finance Indonesia TBK. Jurnal Ekonomi Efektif, 1(2).

Thoha. 2013. Kepemimpinan dan Manajemen. Jakarta : PT Raja Grafindo

Yukl. 2015. Kepemimpinan Dalam Organisasi (Edisi 7). Jakarta : Indeks 